IRA-International Journal of Management \& Social Sciences

ISSN 2455-2267; Vol.06, Issue 02 (2017)

Pg. no. $138-146$

Institute of Research Advances

http://research-advances.org/index.php/RAJMSS

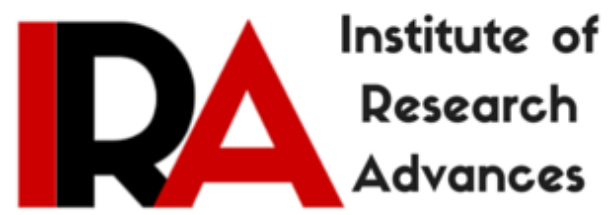

\title{
Brand Equity Analysis of Select Personal Wash Brands Based on Brand Loyalty and Perceptual Selectivity
}

\author{
Amrita Chatterjee $^{1}$ \& Isita Lahiri $^{2}$ \\ ${ }^{1}$ Junior Research Fellow (UGC/NET/JRF) \\ Department of Business Administration, \\ University of Kalyani, Nadia,West Bengal, India. \\ ${ }^{2}$ Professor \\ Department of Business Administration, \\ University of Kalyani, Nadia,West Bengal, India.
}

Type of Review: Peer Reviewed.

DOI: http://dx.doi.org/10.21013/jmss.v6.n2.p2

\section{How to cite this paper:}

Chatterjee, A., \& Lahiri, I. (2017). Brand Equity Analysis of Select Personal Wash Brands Based on Brand Loyalty and Perceptual Selectivity. IRA-International Journal of Management \& Social Sciences (ISSN 2455-2267), 6(2), 138-146. doi:http://dx.doi.org/10.21013/jmss.v6.n2.p2

(C) Institute of Research Advances

(c) EY-NC

This work is licensed under a Creative Commons Attribution-Non Commercial 4.0 International License subject to proper citation to the publication source of the work.

Disclaimer: The scholarly papers as reviewed and published by the Institute of Research Advances (IRA) are the views and opinions of their respective authors and are not the views or opinions of the IRA. The IRA disclaims of any harm or loss caused due to the published content to any party. 


\begin{abstract}
A major part of Marketing is brand building. Once a brand is established in the market it has a positive impact on the sales of the product which is associated with that brand. Now in this process of brand building brand equity becomes the key factor to get the edge over the competitors. Brand equity of FMCG products depends on few factors but here the objective of the study is to analyze brand equity with respect to brand loyalty and perceptual selectivity as the key determinants of brand equity in Indian FMCG market with special reference to some personal wash brands under the category of personal care FMCG products. Some demographic variables are also taken into account to establish the influential effects of these variables on brand equity.
\end{abstract}

Keywords- Brand Equity, Brand Loyalty, Perceptual Selectivity, Personal Wash Brands, FMCG brands.

\title{
INTRODUCTION
}

Now a days Indian market is an open market for most of the foreign companies, so it is very much obvious that the leading brands in world market are now entering in Indian market and the leading Indian brands are already there to give competition to these global brands. Indian FMCG market is also characterized by a well-established distribution channel, intense competition between the organized and unorganized segments of market and low operational cost. Availability of raw materials, cheap labour and its presence across the entire value chain gives India a competitive advantage. Also, increase in the urban population along with the increase in income levels helps the urban areas to maintain their higher position than the rural areas in terms of consumption. FMCG sector is alternatively called as CPG (Consumer packaged goods) industry primarily deals with the production, distribution and marketing of consumer packaged goods. The Fast Moving Consumer Goods (FMCG) is that consumable which is normally consumed by the consumers at a regular interval. Some of the prime activities of FMCG industry are selling, marketing, financing, purchasing, etc. The industry is also engaged in operations, supply chain, production and general management. Brand is the "name, term, design, symbol, or any other feature that identifies one seller's product distinct from those of other sellers" (American Marketing Association , 2011). Brands are used in business, marketing, and advertising. In accounting, a brand, defined as an intangible asset, is often the most valuable asset on a company's balance sheet. It was meant to make identifying and differentiating a product easier while providing the benefit of letting the name sell a second rate product. Today brand plays a much bigger role. The brands are so powerful that they are used to communicate complex messages quickly and with emotional impact and the ability of brands to attract media attention, make them ideal tools in the hands of marketers. In this competitive business environment only brand building is not enough but a brand will have to maintain its position in customers mind. The brands position in customers mind can be reflected through brand equity. In case of FMCG sector, where each and every day new products, new brands are launched by different Indian and Multinational companies, brand equity is becoming an edge of competitive advantage for every player.

Literature Review: Brand equity related study started to get significant attention of marketers and academicians from 1991 with the work of David A. Aker. Since then, brand equity is one of the major points of attention in the field of Marketing. Here the brand equity related literatures are segregated under seven heads. These are as follows:

\section{A. Some Attributes of Brand Equity}

Benchmarking can not only be done in profit related issues but it can also be done in brand building. Objective of each firm is to develop credible measures of brand equity that supplement financial measures with brand asset measures. Brand equity measures should be responsive one a small change in brand equity can be identified by that measure. In this context we can talk about the "Brand Equity Ten", ten sets of measures grouped into five categories. The first four categories represent customer perceptions of the brand along the four dimensions of brand equity-loyalty, perceived quality, associations, and awareness. The fifth includes two sets of market behavior measures that represent information obtained 
from market based information rather than directly from customers (Aaker, 1991).Tapping the 'Brand Equity Ten' could require dozens of measures. Although each potentially has diagnostic value, the use of so many measures is not that much effective. For reporting and tracking purposes, it would be useful and convenient to have a single summary measure or at most a set of four measures. Managers also need to consider that the survey instrument should be identical over markets. Local management in each market may already have its own tested instrument with a history that helps facilitate interpretation. It might be extremely costly both in terms of money and buy-in to add another instrument that is partially redundant and seems to be off target. One solution the management team can adopt for each market create or adapt measures of the major constructs - namely, loyalty, perceived quality, associations/differentiation, and awareness - which could be compared to both a relevant competitor set and to the past. While the marketers will compare scores across markets, the focus would be on changes from the past, and the relative performance with respect to the competitor set (Aaker, 1991).

\section{B. Customer Based Brand Equity}

CBBE can be measured using both direct and indirect approaches. The indirect approach identifies potential sources of brand equity, while the direct approach collects consumer responses towards different elements of firm's marketing program. It is implied from customer-based research that customers' brand perception measurement are accurate reflections of brand performance. Strong and positive CBBE has a significant influence on the firm's financial performance (Keller K. L., 1993). Customer based brand equity has a financial value. The two components of the system are the Consumer Value and the Brand Dynamics Pyramid which identifies value of individual respondents to a brand based on their predicted loyalty based on their attitudes towards that brand. Value share of requirements measure is a key indicator of brand equity because it will reflect both the proportion of volume sales and a degree to which people are ready to pay brand premium .Loyalty is not the sole indicator of value of a purchaser to a brand but weight of consumption should be taken into account. Brand Dynamics Pyramid, examines why a person might have higher loyalty for a brand than another brand. Consumer Value model and then the scores of this model was validated through Brand Dynamics Pyramid (Paul Dyson, 1996). Brand equity is a multidimensional concept and it is a complex phenomenon separated it into two components: Brand Awareness (BAW) and Brand Association (BAS).Strong and positive brand equity means the customers will have high brand-name awareness; they will maintain a favorable brand image and perceive the brand as of high quality, and they will be loyal to the brand (Keller, 2001). Keller has developed the CustomerBased Brand Equity Pyramid to show how you can build a strong brand. The pyramid consists of four different stages. According to (Keller K. L., 2008) the first stage relates to brand identity, and it uses brand salience as a measurement for awareness. In the second stage called brand meaning, it is imperative to establish brand image in the customer's mind. The third stage refers to eliciting the proper consumer response in relation to brand identity and brand meaning. Finally, the aim is to transform brand response into a loyal relationship between the customers and the brand.

\section{Perceptual Selectivity}

Selective perception is the process by which individuals perceive what they want to in media messages while ignoring opposing viewpoints. It is a broad term to identify the behaviour all people exhibit to tend to "see things" based on their particular frame of reference. It also describes how we categorize and interpret sensory information in a way that favours one category or interpretation over another. In other words selective perception is a form of bias because we interpret information in a way that is congruent with our existing values and beliefs. Psychologists believe this process occurs automatically (Emily Pronin, 2007). Selective perception may refer to any number of cognitive biases in psychology related to the way expectations affect perception. Human judgment and decision making is distorted by an array of cognitive, perceptual and motivational biases, and people tend not to recognise their own bias, though they tend to easily recognise (and even overestimate) the operation of bias in human judgment by others. One of the reasons this might occur might be because people are simply bombarded with too much 
stimuli every day to pay equal attention to everything, therefore, they pick and choose according to their own needs (Canosa, R.L., 2009).

\section{DEFINITION OF THE VARIABLES}

In this study two independent variables and one dependent variable is identified.

- Brand equity: Brand equity is a phrase used in the marketing industry which describes the value of having a well-known brand name, based on the idea that the owner of a well-known brand name can generate more money from products with that brand name than from products with a less well known name, as consumers believe that a product with a well-known name is better than products with less well-known names (Aaker, 1991), (Keller, 2003),( Kohli, K.R. Harich, 1995),( Lehmann, et.al, 2003).

- Perceptual selectivity of the consumer: A customer always expects some value from the brand. In case of FMCG products he wants to realize the value while he is using the product. Regular usage of a particular brand generates some expectation in customers mind from that brand. The expectations can be in terms of product design, color, flavor, packaging etc. which he wants to be fulfilled by the brand.

- Brand Loyalty: Brand heritage can be stated as the long term presence of the brand in the market and to have brand heritage a particular brand should have good will in market for several years.

\section{PROBLEM STATEMENT}

After the literature review it can be said that so far brand equity has been associated with some important variables but here in this research article main emphasis is given on brand loyalty and on perceptual selectivity of the consumer as the determinants of brand equity.

\section{OBJECTIVES}

- Main objective of this study is to find out the relationship of Brand equity with Brand loyalty and perceptual selectivity of the consumer for a particular set of FMCG brands.

- Analysis of customers' response to know their perception about brand equity of FMCG products based on bathing soap brands.

\section{RESEARCH METHODOLOGY}

\section{A. Sampling Procedure}

This phase of the study comprised a surveyheld amongst FMCG consumers. A sample of 100 respondents is selected for this pilot study. The sample is drawn from Kolkata and adjacent areas. The sample is consisted of respondents from different age groups and from different socio economic classes. The rationalefor selecting a sample with such characteristicsis that the sample:

- Sets a minimum educational level for entry into the research

- Represents a segment that is more informed about their choices and preferences

- Represents a community that is more likely to analyze their own purchasing behavior

- Representslower to higher income earnersthat have a wider choice of brands toconsider in their purchasing decision and they would be able to understand the terminology and nomenclature specified in the questionnaire.

\section{B. Data Collection}

The questionnaire is developed to capture the data. The responses on the questions are recorded on a 5point Interval scale. Respondents were asked to rate their favorite brand of bathing soap from 1 to 5 
where 1 is the lowest rate and 5 is the highest rate. In this process the data generated is in interval scale. Brand equity is assessed based on two variables brand loyalty and perceptual selectivity of the consumer. Other questions which indicate respondent's demographic and socioeconomic situations are in the form of multiple choice questions.

\section{Sample Design}

In this study the total number of respondents $=100$. This sample is consists of people from different age groups. The following table shows the distribution of respondents based on their ages. The whole sample is divided in 4 different age groups.

TABLE 1

AGE OF RESPONDENTS

\begin{tabular}{|l|l|}
\hline Age of Respondents & Number of respondents \\
\hline $18-23$ years & 25 \\
\hline $24-35$ years & 30 \\
\hline $36-50$ years & 30 \\
\hline $50-60$ years & 15 \\
\hline
\end{tabular}

The sample is divided into two groups based on their gender; male and female. In our study number of male respondents is less than number of female respondents. The respondents are selected randomly so this variation is completely coincidental.

Whole sample is again divided into three economic classes and the following table shows the distribution of respondents as per their monthly income.

TABLE 2

LEVEL OF INCOME OF THE RESPONDENTS

\begin{tabular}{|l|l|}
\hline Level of income/ month in Rs. & Number of respondents \\
\hline Bellow 5000 & 25 \\
\hline $5000-15000$ & 45 \\
\hline More than 15000 & 30 \\
\hline
\end{tabular}

\section{Data Analysis}

Data analysis is mainly done to identify the relationship of brand equity of bathing soap brands with brand loyalty andperceptual selectivity of the consumer. Multiple regression analysis has been done for this purpose. The statistical functions are performed by using SPSS 16. 
TABLE 3

DIFFERENT BRANDS OF BATHING SOAPS AND NUMBER OF RESPONDENTS USING A PARTICULAR BRAND

\begin{tabular}{|l|l|}
\hline $\begin{array}{l}\text { Name of the bathing soap } \\
\text { brand }\end{array}$ & $\begin{array}{l}\text { Number of loyal respondents purchased a brand for more than } 5 \\
\text { times. }\end{array}$ \\
\hline Lux & 45 \\
\hline Dove & 25 \\
\hline Fiama Di Wills & 5 \\
\hline Life Buoy & 15 \\
\hline Other & 10 \\
\hline
\end{tabular}

From table 3 it is apperant that Lux has highest number customers where as Fiama Di Wills has the lowest number of customers. Here the analysis has been done to understand the reason behind the brand equity for the bathing soap brand which the individual respondents have purchased and used atleast for 5 times.

TABLE 4

VARIABLES ENTERED/REMOVED AT THE TIME OFOF DATA ANALYSIS

\begin{tabular}{|l|l|l|l|}
\hline Model & $\begin{array}{l}\text { Variables } \\
\text { Entered }\end{array}$ & $\begin{array}{l}\text { Variables } \\
\text { Removed }\end{array}$ & Method \\
\hline 1 & $\begin{array}{l}\text { Brand Loyalty } \\
\text { Perceptual } \\
\text { selectivity }\end{array}$ & Enter \\
\hline a. All requested variables entered. & \\
\hline b. Dependent Variable: Brand Equity & \\
\hline
\end{tabular}

Table 4 shows that all the variables which are considered at the time of analysis are taken into account at the time of calculation.

TABLE 5

MODEL SUMMARY

\begin{tabular}{|c|c|c|c|c|}
\hline Model & $\mathrm{R}$ & R Square & \begin{tabular}{|lr} 
Adjusted & $\mathrm{R}$ \\
Square & \\
\end{tabular} & Std. Error of the Estimate \\
\hline 1 & $.838^{\mathrm{a}}$ & .703 & .694 & .682 \\
\hline
\end{tabular}

a. Predictors: (Constant), Brand Loyalty, Perceptual selectivity

c. Dependent Variable: Brand Equity 
From Table 5 the model summary shows that the coefficient of multiple determinant $\mathrm{R}$ Square value is 0.703.That means $70.3 \%$ of the variation in the dependent variable is explained by independent variable. It can be said that the regression equation useful for making predictions since the value of $\mathrm{R}$ Square value is close to 1 .

TABLE 6

COEFFICIENTS OF BRAND LOYALTY AND PERCEPTUAL SELECTIVITY

\begin{tabular}{|c|c|c|c|c|c|c|c|}
\hline \multirow{2}{*}{\multicolumn{2}{|c|}{ Model }} & \multicolumn{2}{|c|}{ Unstandardized Coefficients } & \multirow{2}{*}{\begin{tabular}{|l} 
Standardized \\
Coefficients
\end{tabular}} & \multirow[b]{2}{*}{$\mathbf{t}$} & \multirow[b]{2}{*}{ Sig. } & \multirow[b]{2}{*}{ VIF } \\
\hline & & B & Std. Error & & & & \\
\hline \multirow[t]{3}{*}{1} & (Constant) & .633 & .306 & & 2.067 & .043 & \\
\hline & Brand Loyalty & .841 & .071 & .841 & 11.850 & .000 & 1.135 \\
\hline & $\begin{array}{l}\text { Perceptual } \\
\text { Selectivity }\end{array}$ & .706 & .061 & .007 & .103 & .001 & 1.135 \\
\hline
\end{tabular}

DependentVariable: Brand Equity

Let's focus on the two predictors, whether they are statistically significant and, if so, the direction of the relationship. The variable perceptual selectivity, $b=0.706$ is significant $(p=0.001)$ and the coefficient is negative which would indicate that perceptual selectivity about the bathing soap brands in consumer's mind is related to higher brand equity.But at the time of one to one interview with the respondents we come to know that perceptual selectivity can be negative for some brands because this determinant of brand equity leads to bias about the brand selection. Next, the effect of brand loyalty $(b=.841, p=.000)$ is significant and it's coefficient is positive indicating that brand loyalty is another key determinant of brand equity. The VIF values of both independent variables are less than 2 so it can be said that no multicollinearity exists between these two.

So the regression equation is $\mathrm{Y}=0.633+0.841 \mathrm{X} 1+0.706 \mathrm{X} 2$

\section{FINDINGS}

From the data analysis some major findings have come out

- Brand loyalty of bathing soap brands regulates brand equity of those brands.

- Perceptual selectivity of the consumer influences the purchase behaviour of the brand and in this process it regulates brand equity.

\section{CONCLUSION}

From previous research works we have identified two variables brand loyalty and perceptual selectivity. In our study we collected responses from different people of different age group and of different income levels based on their selection of bathing soap brands as a FMCG product. Qualitative and quantitative analysis of their responses proved that brand equity positively depends on brand loyalty and perceptual selectivity of the consumers about the bathing soap brands. According to our study Lux has the highest loyal customer base which is followed by Dove and Life Buoy which implies Lux is enjoying highest brand equity. From the responses of the customers of above mentioned bathing soap brands it can be identified that perceptual selectivity of their mind is another key factor of brand equity.

\section{LIMITATION}

This study is based on the responses of 100 respondents. So the findings of this study cannot be generalized. 


\section{SCOPE OF FURTHER RESEARCH}

There is ample scope of further research by making the sample size large. This study can be extended by extending the product category.

\section{REFERENCES}

1. Steven Lucas Counselling. (2009, December 29). Psychology Definition Of The Week : Selective Perception. Retrieved March 18, 2013, from http://counsellingcentral.com/psychology-definitionof-the-week-selective-perception/

2. Emily Pronin, "Perception and misperception of bias in human judgment," Trends in Cognitive Sciences, Volume 11, Issue 1, January 2007, pp. 37-43.

3. Canosa, R.L. (2009). Real-world vision: selective perception and task. ACM Trans. Appl. Percpt., 6, 2, Article 11, 34 pages.

4. David A. Aaker, Managing Brand Equity (New York, NY: The Free Press, 1991

5. Ahmed I. Moolla1, 2. a. (2012). Empirical Evaluation of a Model That Measures the Brand. Soc Sci .

6. Back KJ, Parks SC 2003. A brand loyalty model involving cognitive, affective, and cognitive brand loyalty and customer satisfaction. Journal of Hospitalityand Tourism Research, 27(4): 419435.

7. Chaudhuri A, Hoibrook MB 2002. The chain of effects from brand trust and brand affect to brand performance: The role of brand loyalty. Journal of Marketing, 65(2): 141-149.

8. Dick AS, Basu K 1994. Customer loyalty: Toward an integrated model. Journal of the Academy of MarketingScience, 22(2): 99-113.

9. Engels 2005 J How Can You Loyalty?From:<http://mktg.unisvishtov.bg/ivm/resources/How\%20Can\%20You\%20Measure\%2 0Loyalty.pdf> (Retrieved on January 23, 2014).

10. Garbarino E, Johnson MS 1999. The different roles of satisfaction, trust, and commitment in customer relationships. Journal of Marketing,63(2): 70-87.

11. Gordon ME, McKeage K, Fox MA 1998. Relationship marketing effectiveness: The role of involvement. Psychology and Marketing, 15(5): 39-45

12. Hess J 1995. Construction and assessment of a scale to measure consumer trust. AMA Educators' Conference,Enhancing Knowledge Development inMarketing, 6(1): 20-25.

13. Hair JF, A. R. (1998). Multivariate Data Analysis. Upper Saddle River,: Prentice-Hall.

14. Jacoby, J. C. (1978). A Behavioral Process Approach to Informal Acquisition in Nondurable Purchasing. Journal of Marketing Research.

15. JE, S. (2010). What is FMCG All About? From <http://enzinearticles.com>(Retrived on 21st January 2014).

16. Jacoby J 1971. A model of multi-brand loyalty. Journal of Advertising Research, 11(3): 25-31.

17. Jacoby J, Chestnut R 1978. Brand Loyalty: Measurement and Management. New York, NY: JohnWiley.

18. Klemperer PD 1987. Markets with consumer switching costs. Quarterly Journal of Economics, 102: 375-394.

19. Kotler P, Keller KL 2006. Marketing Management. 12th Edition. London: Prentice Hall.

20. Miller DW, Marks LJ 1996. The moderating effects of enduring involvement on imagery-evoking advertisements. American Marketing Association, 121- 128. 
21. Odekerken-Schröder G 1999. The Role of the Buyer in Affecting Buyer-seller Relationships: Empirical Studies in a Retail Context. Ph.D Thesis, Unpublished. Maastricht: Maastricht. University.

22. Punniyamoorthy M, Raj PM 2007. An empirical model for brand loyalty measurement. Journal of Targeting,Measurement and Analysis for Marketing, 15(4): 222-233.

23. Saaty TL 1994. How to make a decision: The analytic hierarchy process. Interfaces, 24(6): 19-43.

24. Sahay A, Sharma J 2010. Brand relationships and switching behaviour for highly used products in young consumers. Vikalpa, 35(1): 1-30.

25. Schijins JMC 2003. Loyalty and satisfaction in physical and remote service encounters. Bedrijfskunde, 74(1): 57-65.

26. Sharp B, Wright M, Goodhardt G 2003. Purchase loyalty is polarised into either repertoire or subscription patterns. Australasian Marketing Journal, 10(3): 7-20.

27. Smith JE 2010. What is FMCG All About? From <http: //enzinearticles.com> (Retrieved on January 5, 2014).

28. Storbacka K, Strandvik T, Grönroos C 1994. Managing customer relationships for profit: The dynamics of relationship quality. International Journal of Service Industry Management, 5(5): 2138.

29. Westbrook RA, Oliver RL 1991. The dimensionality of consumption emotion patterns and customer satisfaction. Journal of Consumer Research, 18(1): 84-91. 